\title{
Case Ascertainment Uncertainties in Prevalence Surveys of Parkinson's Disease
}

\author{
Dallas W. Anderson, PhD, *†Walter A. Rocca, MD, MPH, $\ddagger$ Maarten C. de Rijk, MD, PhD, \\ IFrancesco Grigoletto, ScD, §Mario O. Melcon, MD, ‡Monique M. B. Breteler, MD, PhD, and \\ $\dagger$ Demetrius M. Maraganore, MD
}

\begin{abstract}
Biometry and Field Studies Branch, National Institute of Neurological Disorders and Stroke, Bethesda, Maryland, U.S.A.; Departments of *Health Sciences Research and +Neurology, Mayo Clinic and Mayo Foundation, Rochester, Minnesota, U.S.A.; $\ddagger$ Department of Epidemiology and Biostatistics, and "Department of Neurology and Erasmus Center for Research on Aging, Erasmus University Medical School, Rotterdam, the Netherlands; IIInstitute of Hygiene, University of Padua, Padua, Italy; and \$epartment of Neurology, Regional Hospital, Junin, Buenos Aires Province, Argentina
\end{abstract}

Summary: Using unpublished data from five completed prevalence surveys of Parkinson's disease (PD), we investigated case ascertainment uncertainties that potentially have a direct effect on prevalence. These uncertainties arise from the choice of diagnostic criteria, the choice of screening method, and the amount of information lost because of nonresponse. The surveys were conducted in Argentina, India, China, Italy, and the Netherlands. Our analyses consisted of simple comparisons of prevalence results, positive predictive values (a screening measure), and nonresponse percentages. We found that (a) prevalence comparisons between surveys have diminished value if the surveys used different diagnostic criteria for PD; (b) screening performance may be affected adversely if symptom questions are answered by one family member for the entire family living together rather than by each family member individually; and (c) nonresponse from refusal or unavailability does not necessarily lead to bias, but special caution may be appropriate with prevalence results pertaining to elderly women. Key Words: Bias-Epidemiology-ParkinsonismParkinson's disease-Prevalence.
Prevalence surveys of Parkinson's disease (PD) continue to be of interest because of a possible environmental role in the etiology of this condition. ${ }^{1}$ Although case ascertainment is central to these surveys, there may be uncertainties about it that remain mostly hidden. Consequently, in published reports, prevalence results are compared and conclusions drawn without always being warranted.

In this article, we consider the relationship between prevalence and case ascertainment uncertainties. Specifically, we address three questions: Do prevalence comparisons between surveys have diminished value if the surveys used different diagnostic criteria for PD? Is screening performance affected adversely if symptom questions are answered by one family member for the

Received September 24, 1997; revision received February 5, 1998 Accepted March 10, 1998.

Address correspondence and reprint requests to Dr. Dallas W. Anderson at the National Institutes of Health, National Institute of Neurological Disorders and Stroke, Federal Building, Room 7C-16, Bethesda, MD 20892-9135, U.S.A. entire family living together rather than by each family member individually? Does nonresponse from refusal or unavailability lead to a bias in prevalence results? For our analyses, we used unpublished data from five completed prevalence surveys of PD conducted in the 1980s or 1990s in Argentina, ${ }^{2,3}$ India, ${ }^{4}$ China,,${ }^{5}$ Italy, ${ }^{6-9}$ and the Netherlands. ${ }^{10}$

\section{METHODS}

The major features of the five surveys are summarized in Table 1. Because of data limitations, it was impossible to use all the surveys jointly to address specific topics.

The Argentina survey, ${ }^{2,3}$ the India survey, ${ }^{4}$ and the China survey ${ }^{5}$ were used to consider diagnostic criteria. Age-specific prevalence comparisons, original and revised, were made for the Argentina survey versus the India survey. They were also made for the Argentina survey versus the China survey. In the original comparisons, the diagnostic criteria given in Table 1 were used. In the revised comparisons, the cases of the Argentina 
TABLE 1. Summary of prevalence surveys of Parkinson's disease (PD) that were conducted in Argentina, India, China, Italy, and the Netherlands

\begin{tabular}{|c|c|c|c|c|c|}
\hline Features & Argentina & India & China & Italy & The Netherlands \\
\hline Survey site(s) & $\begin{array}{l}\text { A city in Buenos } \\
\text { Aires Province }\end{array}$ & $\begin{array}{l}\text { All Parsi colonies } \\
\text { of Greater } \\
\text { Bombay }\end{array}$ & $\begin{array}{l}\text { Selected } \\
\text { communities } \\
\text { of six cities }\end{array}$ & $\begin{array}{l}\text { Three Sicilian } \\
\text { municipalities }\end{array}$ & A Rotterdam suburb \\
\hline $\begin{array}{l}\text { Intended } \\
\text { inclusion }\end{array}$ & $\begin{array}{l}\text { Sample of } \\
\text { residents aged } \\
\geqslant 40 \text { yrs (as } \\
\text { of Jan } 1,1991 \text { ) }\end{array}$ & $\begin{array}{l}\text { All residents who } \\
\text { are Parsis (as of } \\
\text { Mar 1, 1985) }\end{array}$ & $\begin{array}{l}\text { Sample of } \\
\text { residents (as of } \\
\text { Jan 1, 1983) }\end{array}$ & $\begin{array}{l}\text { All residents (as } \\
\text { of Nov } 1,1987 \text { ) }\end{array}$ & $\begin{array}{l}\text { All residents aged } \geqslant 55 \\
\text { yrs (from } 1990 \\
\text { population register) }\end{array}$ \\
\hline Screening & $\begin{array}{l}\text { Questions only; } \\
\text { one individual } \\
\text { responded for } \\
\text { family members } \\
\text { living together }\end{array}$ & $\begin{array}{l}\text { Questions only; one } \\
\text { individual } \\
\text { responded for } \\
\text { family members } \\
\text { living together }\end{array}$ & $\begin{array}{l}\text { Questions/tasks; } \\
\text { individuals } \\
\text { responded for } \\
\text { themselves }\end{array}$ & $\begin{array}{l}\text { Questions/tasks; } \\
\text { individuals } \\
\text { responded for } \\
\text { themselves }\end{array}$ & $\begin{array}{l}\text { Questions/brief } \\
\text { neurologic examination; } \\
\text { individuals responded } \\
\text { for themselves }\end{array}$ \\
\hline $\begin{array}{l}\text { Screening } \\
\text { personnel }\end{array}$ & $\begin{array}{l}\text { Medically } \\
\text { unsophisticated } \\
\text { interviewers }\end{array}$ & $\begin{array}{l}\text { Medically } \\
\text { unsophisticated } \\
\text { interviewers }\end{array}$ & Not reported & Physicians & $\begin{array}{l}\text { Medically unsophisticated } \\
\text { interviewers (questions) } \\
\text { and physicians } \\
\text { (examinations) }\end{array}$ \\
\hline $\begin{array}{l}\text { Neurologic } \\
\text { evaluation of } \\
\text { persons } \\
\text { screened } \\
\text { positive for } \\
\text { parkinsonism }\end{array}$ & $\begin{array}{c}\text { Standardized } \\
\text { diagnostic } \\
\text { protocol }\end{array}$ & $\begin{array}{c}\text { Standardized } \\
\text { diagnostic } \\
\text { protocol }\end{array}$ & $\begin{array}{c}\text { Standardized } \\
\text { diagnostic } \\
\text { protocol }\end{array}$ & $\begin{array}{c}\text { Standardized } \\
\text { diagnostic } \\
\text { protocol }\end{array}$ & $\begin{array}{l}\text { Standardized } \\
\text { diagnostic } \\
\text { protocol }\end{array}$ \\
\hline $\begin{array}{l}\text { Diagnostic criteria } \\
\text { for PD }\end{array}$ & $\begin{array}{l}\text { At least two of the } \\
\text { following } \\
\text { cardinal signs: } \\
\text { resting tremor, } \\
\text { bradykinesia, } \\
\text { rigidity, impaired } \\
\text { postural reflexes; } \\
\text { one sign must be } \\
\text { resting tremor or } \\
\text { bradykinesia; } \\
\text { other causes } \\
\text { of parkinsonism } \\
\text { must not be } \\
\text { apparent }\end{array}$ & $\begin{array}{l}\text { At least three of the } \\
\text { following } \\
\text { cardinal signs: } \\
\text { resting tremor, } \\
\text { bradykinesia, } \\
\text { rigidity, impaired } \\
\text { postural reflexes; } \\
\text { other causes } \\
\text { of parkinsonism } \\
\text { must not be } \\
\text { apparent }\end{array}$ & $\begin{array}{l}\text { At least two of } \\
\text { the following } \\
\text { cardinal signs: } \\
\text { resting tremor, } \\
\text { bradykinesia, } \\
\text { rigidity; one } \\
\text { sign must be } \\
\text { resting tremor; } \\
\text { other causes } \\
\text { of parkinsonism } \\
\text { must not be } \\
\text { apparent }\end{array}$ & $\begin{array}{l}\text { At least two of the } \\
\text { following cardinal } \\
\text { signs: resting tremor, } \\
\text { bradykinesia, } \\
\text { rigidity, impaired } \\
\text { postural reflexes; } \\
\text { only one sign } \\
\text { needed if subject is } \\
\text { receiving } \\
\text { antiparkinsonian } \\
\text { therapy; other } \\
\text { causes of } \\
\text { parkinsonism } \\
\text { must not be } \\
\text { apparent }\end{array}$ & $\begin{array}{l}\text { At least two of the } \\
\text { following cardinal signs: } \\
\text { resting tremor, } \\
\text { bradykinesia, rigidity, } \\
\text { impaired postural } \\
\text { reflexes; only one sign } \\
\text { needed if subject is } \\
\text { receiving and } \\
\text { benefitting from } \\
\text { antiparkinsonian } \\
\text { therapy; other } \\
\text { causes of } \\
\text { parkinsonism } \\
\text { must not be } \\
\text { apparent }\end{array}$ \\
\hline
\end{tabular}

survey were reclassified according to the more restrictive diagnostic criteria of the India survey, and also according to the more restrictive diagnostic criteria of the China survey. Data were unavailable to make a three-way prevalence comparison with each survey using the same set of diagnostic criteria.

The Argentina survey ${ }^{2,3}$ and the Italy survey ${ }^{6-9}$ were used to consider screening methods. In the Argentina survey, screening was based exclusively on interviews. One family member in a household would respond about all the family members living together in that household. By contrast, in the Italy survey, screening was based on direct interviews and performance of simple physical tasks. Individuals responded for themselves. Details of the two screening methods have been published elsewhere. ${ }^{2,6}$ The positive predictive values (PPVs) for individual screening items were compared within and be- tween the surveys for men and women separately. The PPV is the percentage of persons with parkinsonism among all persons screened as positive on the basis of a given item. To increase comparability between the surveys, we computed PPVs limited to persons 40 years of age or older.

The Italy survey ${ }^{6-9}$ and the Netherlands survey ${ }^{10}$ were used to consider nonresponse. Nonresponse pertains to persons selected for inclusion but who do not participate. In the Italy survey, screening for PD consisted of both an interview and two simple physical tasks: the subject had to walk heel-to-toe and to allow elbow manipulation (to assess muscle tone). However, only the interview was necessary to satisfy the response requirement. The interview could be completed by the subject or by a relative (that is, a proxy respondent) who answered in regard to the subject. In the Netherlands survey, the screening for 
A

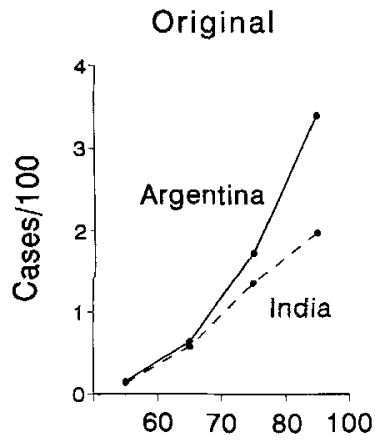

B

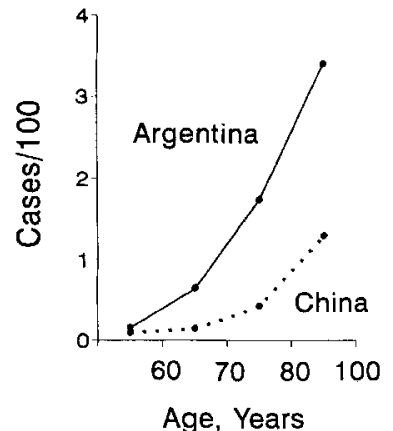

FIG. 1. Parkinson's disease prevalence: (A) Argentina survey versus India survey; (B) Argentina survey versus China survey. In the "original" comparisons, the diagnostic criteria were those given in Table 1. In the "revised" comparisons, the Argentine cases were reclassified to follow the diagnostic criteria of the India survey and then those of the China survey.

PD was based on a brief neurologic examination that addressed the presence or absence of bradykinesia, resting tremor, rigidity, and impaired postural reflexes. This examination was conducted at a central research facility and was necessary to satisfy the response requirement. Subjects were also interviewed directly about the possible presence of PD, but this alone was insufficient for them to be included as responders.

In addition to the actual response requirements of the two surveys, we considered alternative response requirements. For the Italy survey, the alternative requirement was that the subject personally complete both the interview and the physical tasks (no proxy respondents allowed). This requirement was more stringent than the one actually used. For the Netherlands survey, the alternative requirement was that the subject personally complete the interview but not necessarily the examination. This requirement was less stringent than the one actually used.

In both the Italy survey and the Netherlands survey, population registers provided the age and sex of each person who was a nonresponder. Separately for the actual and the alternative response requirements, we defined age-sex classes and computed for each class the percentage of nonresponders among all persons selected for inclusion. We then compared age- and sex-specific patterns of prevalence and nonresponse within each survey.

\section{RESULTS}

\section{Diagnostic Criteria}

The age-specific prevalence patterns of PD for the Argentina survey ${ }^{2,3}$ and the India survey ${ }^{4}$ diverged with advancing age (Fig. 1, upper left). The two surveys, however, used different diagnostic criteria (Table 1). With the same diagnostic criteria (those of the India survey), the difference in patterns largely disappeared (Fig. 1, upper right). Specifically, for persons aged 70-79 years, the Argentine prevalence changed from $1.7 \%$ to $1.4 \%$, becoming identical to the Indian prevalence of $1.4 \%$. For persons 80 years of age or older, the Argentine prevalence changed from $3.4 \%$ to $2.3 \%$, approaching the Indian prevalence of $2.0 \%$.

For the Argentina survey ${ }^{2,3}$ and the China survey, disparate prevalence patterns persisted when both surveys used the same diagnostic criteria (those of the China survey; Fig. 1, bottom half).

\section{Symptom Screening}

In both the Argentina survey ${ }^{2,3}$ and the Italy survey, ${ }^{6-9}$ participants were asked not only about symptoms of PD but also whether they had PD. Reporting of the presence of PD gave the highest positive predictive values (PPVs) within each survey: Argentina, 88\%; Italy, $80 \%$.

There were 10 symptom questions in the Argentina survey and two symptom questions in the Italy survey. The PPVs for the symptom questions of the Argentina survey ranged from 35-82\% (Table 2). The question with the highest PPV $(82 \%)$ addressed permanent muscular rigidity in the arms and legs. By contrast, the PPVs for the symptom questions of the Italy survey were $18 \%$ and $33 \%$ (Table 2). The question with the highest PPV (33\%) addressed tremor of the head, arms, and legs. Of the 12 symptom questions taken together, 11 showed the PPV for men exceeding or equaling the PPV for women (Table 2). The exception, from the Argentina survey, was a question about speaking in a low and muffled voice.

In addition to two symptom questions, the Italy survey had two screening items related to simple physical tasks. The PPVs for the tasks, $14 \%$ and $31 \%$, were approximately the same as the PPVs for the symptom questions, $18 \%$ and $33 \%$ (Table 2). 
TABLE 2. Screening for parkinsonism: positive predictive values from the Argentina survey and the Italy survey* $\uparrow$

\begin{tabular}{|c|c|c|c|}
\hline \multirow[b]{2}{*}{ Item } & \multicolumn{3}{|c|}{ Positive predictive value $(\% ;$ no. true positives/no. total positives) } \\
\hline & Men & Women & All \\
\hline \multicolumn{4}{|l|}{ Argentina survey (questions only) } \\
\hline Trembling of hands or legs & $59.3(32 / 54)$ & $35.0(28 / 80)$ & $44.8(60 / 134)$ \\
\hline Trembling of head or jaw & $50.0(7 / 14)$ & $27.6(8 / 29)$ & $34.9(15 / 43)$ \\
\hline $\begin{array}{l}\text { Permanent muscular rigidity in the arms or legs } \\
\text { (not because of swelling, arthritis, or rheumatism) }\end{array}$ & $83.3(25 / 30)$ & $80.0(20 / 25)$ & $81.8(45 / 55)$ \\
\hline $\begin{array}{l}\text { Difficulty standing from a sitting position (not because of severe pain in } \\
\text { the legs) }\end{array}$ & $78.1(25 / 32)$ & $51.4(18 / 35)$ & $64.2(43 / 67)$ \\
\hline $\begin{array}{l}\text { Walking more slowly than others of similar age (not because of an } \\
\text { operation on hips, knees, or legs) }\end{array}$ & $59.6(28 / 47)$ & $45.6(26 / 57)$ & $51.9(54 / 104)$ \\
\hline Difficulty in stopping when walking or running because legs will not obey & $63.6(14 / 22)$ & $58.1(18 / 31)$ & $60.4(32 / 53)$ \\
\hline Taking longer than before to get dressed & $66.7(36 / 54)$ & $52.6(30 / 57)$ & $59.5(66 / 111)$ \\
\hline Clumsy fingers when buttoning clothing & $75.0(30 / 40)$ & $50.9(28 / 55)$ & $61.1(58 / 95)$ \\
\hline Handwriting that has gradually gotten smaller and jerkier & $75.0(21 / 28)$ & $55.2(16 / 29)$ & $64.9(37 / 57)$ \\
\hline Speaking in a low and muffled voice that is hard to understand & $58.3(7 / 12)$ & $73.3(11 / 15)$ & $66.7(18 / 27)$ \\
\hline \multicolumn{4}{|l|}{ Italy survey (questions and tasks) } \\
\hline Rigidity or slowness of movement (question) & $21.5(32 / 149)$ & $16.1(34 / 211)$ & $18.3(66 / 360)$ \\
\hline Tremor of head, arms, or legs (question) & $33.7(30 / 89)$ & $33.0(38 / 115)$ & $33.3(68 / 204)$ \\
\hline Walking heel-to-toe (task) & $12.3(15 / 122)$ & $14.9(22 / 148)$ & $13.7(37 / 270)$ \\
\hline Muscle tone evaluation by manipulating the subject's arms (task) & $29.9(35 / 117)$ & $32.0(40 / 125)$ & $31.0(75 / 242)$ \\
\hline
\end{tabular}

* Pertains to persons 40 years of age or older.

$\dagger$ The positive predictive values are best used for screening item comparisons within surveys. Comparisons between the surveys are generally difficult to interpret because of inherent differences in the screening methods.

\section{Nonresponse}

In the Italy survey, ${ }^{6-9}$ there were 7493 eligible persons who were 50 years of age or older. Of these, 6782 satisfied the actual response requirement (that is, they completed the screening interview with or without the aid of a proxy respondent). There were 63 prevalent cases of $\mathrm{PD}$, and the nonresponse percentage was $9 \%$. By contrast, 6384 persons satisfied the alternative response requirement (that is, they personally completed the screening interview and two physical tasks). Under this more stringent requirement, there were 61 prevalent cases of $\mathrm{PD}$, and the nonresponse percentage was $15 \%$.

In the Netherlands survey, ${ }^{10}$ there were 10,275 eligible persons who were 55 years of age or older. Of these, 6969 satisfied the actual response requirement (that is, they completed the neurologic screening examination at a central research facility). There were 97 prevalent cases of $\mathrm{PD}$, and the nonresponse percentage was $32 \%$. By contrast, 7753 persons satisfied the alternative response requirement (that is, they personally completed the screening interview but not necessarily the neurologic screening examination). Under this less stringent requirement, the nonresponse percentage was $25 \%$.

For both the Italy survey and the Netherlands survey, the nonresponse percentages were higher for older persons than for younger persons regardless of the response requirements (Figs. 2 and 3). The more stringent response requirements led to the following: (a) consistently higher nonresponse percentages across all ages than those obtained with the less stringent response requirements (Figs. 2 and 3); (b) generally higher nonresponse percentages for older women than for older men, especially in the Netherlands survey (Figs. 2 and 3); and (c) nonresponse percentages exceeding $60 \%$ for the oldest women (Figs. 2 and 3).

In terms of prevalence, both surveys showed similar increases with age (Figs. 2 and 3). The highest prevalence occurred in older persons as did the largest nonresponse. For the Italy survey, two prevalence patterns are presented: the actual prevalence (based on a less stringent response requirement) and the alternative prevalence (based on a more stringent response requirement; Fig. 2). There is little difference in the patterns except for older women. For the Netherlands survey, only the actual prevalence pattern is presented (based on a more stringent response requirement; Fig. 3). The alternative prevalence (based on a less stringent response requirement) could not be computed because diagnostic data were lacking for persons who completed only the screening interview.

\section{DISCUSSION}

\section{Diagnostic Criteria}

In searching for etiologic clues about PD, it may be useful to make prevalence comparisons between surveys. Such comparisons have scientific value if high prevalence indicates high risk and low prevalence indicates low risk. However, differences in prevalence between 

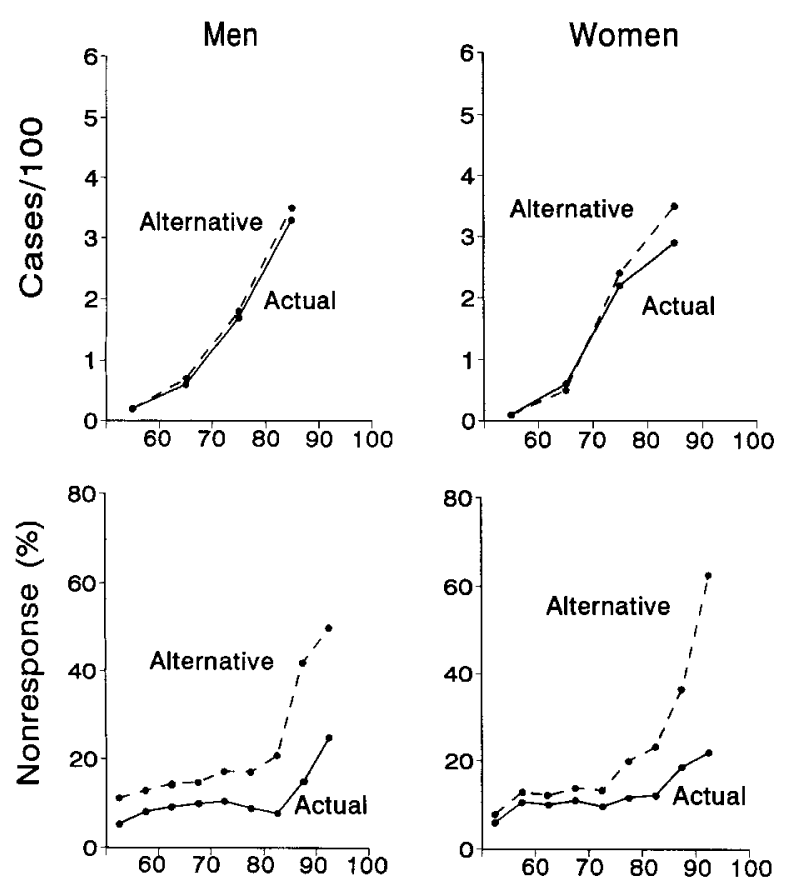

Age, Years

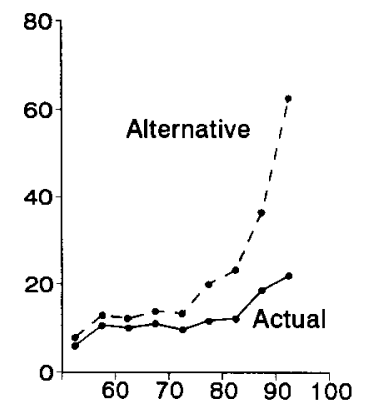

Age, Years

FIG. 2. Parkinson's disease prevalence and nonresponse in the Italy survey. The actual prevalence and the actual nonresponse were based on the response requirement used in the survey: to be a responder, the subject (or a proxy respondent) must have completed the screening interview but not necessarily the two physical tasks. The alternative prevalence and the alternative nonresponse were based on a more stringent response requirement (not used in the survey): to be a responder, the subject must have personally completed the screening interview and the two physical tasks (no proxy respondent allowed).

surveys may be more related to artifacts than to risk. Our comparison between the Argentina survey ${ }^{2,3}$ and the India survey ${ }^{4}$ (Fig. 1) showed that, at least in some instances, differences in prevalence between surveys may be largely explained by differences in diagnostic criteria. On the other hand, the comparison between the Argentina survey ${ }^{2,3}$ and the China survey ${ }^{5}$ (Fig. 1) is a reminder that substantial differences in prevalence between surveys may be the result of reasons unrelated to diagnostic criteria.

\section{Symptom Screening}

In many surveys of $\mathrm{PD}$, the credibility of prevalence results depends greatly on the validity of the screening method used. Sensitivity and specificity are measures of that validity. Sensitivity refers to the probability of correctly identifying any case, whereas specificity refers to the probability of correctly identifying any non-case. ${ }^{11}$ Estimates of sensitivity and specificity are usually derived from pilot investigations and they may be problematic. Because of unrealistic testing (for example, with

hospitalized cases only), the estimates tend to indicate a better performance of the screening method than would happen in the actual survey.

The symptom screening methods of the Argentina survey $^{2,3}$ and the Italy survey ${ }^{6-9}$ were, in fact, deemed valid on the basis of pilot investigations. ${ }^{3,8}$ In both surveys, the overall sensitivity estimate for parkinsonism was $100 \%$ (Argentina, 24 of 24; Italy, 21 of 21). Sensitivity estimates for individual screening items are unavailable for the Argentina survey but have been published for the Italy survey. ${ }^{8}$ The highest sensitivity estimate, exceeding $90 \%$, was for rigidity or slowness of movement.

The PPVs (see Methods) give another perspective on screening performance, and they are obtained from the actual surveys. When a PPV is computed for a particular symptom, it indicates the probability that a person has parkinsonism, given that he or she has that symptom. The symptom PPVs were strikingly higher in the Argentina survey than in the Italy survey (Table 2 ). This pattern, however, is somewhat misleading because only one symptom question, about trembling or tremor, was di-
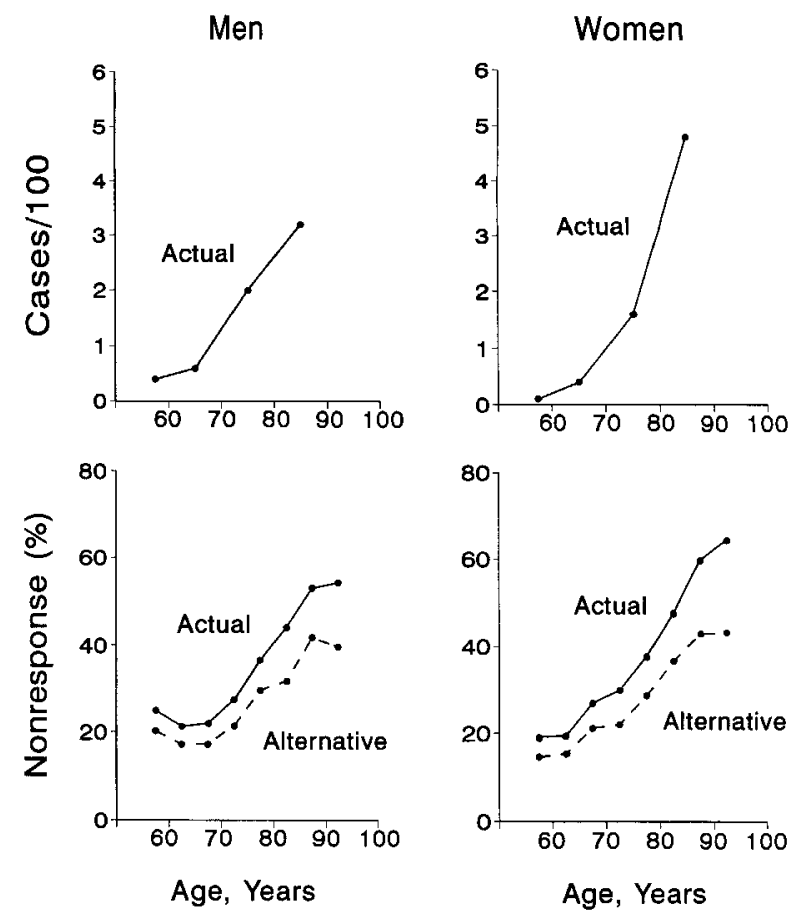

FIG. 3. Parkinson's disease prevalence and nonresponse in the Netherlands survey. The actual prevalence and the actual nonresponse were based on the response requirement used in the survey: to be a responder, the subject must have completed the neurologic screening examination at a central research facility. The alternative nonresponse was based on a less stringent response requirement (not used in the survey): to be a responder, the subject must have personally completed the screening interview but not necessarily the screening examination. The alternative prevalence was not computed because diagnostic data were lacking for those subjects who completed only the screening interview. 
rectly comparable between the two surveys. For that question, the PPVs were similar: 35\% and 45\% for Argentina; and $33 \%$ for Italy (Table 2). In the Argentina survey, the symptom question with the highest PPV addressed permanent muscular rigidity in the limbs (Table 2). This question had a built-in exclusion of persons whose muscular rigidity was reported to be from swelling, arthritis, or rheumatism. Because of this exclusion, the PPV was higher than it would have been otherwise.

The comparatively high PPVs in the Argentina survey may have a general explanation. In that survey, the symptoms in one family member were usually identified by another family member. This approach, compared with self-reporting, would imply a reporting of fewer minor symptoms, which, in turn, would imply higher PPVs. For symptom questions, the higher PPVs in men (Table 2) may be related to a gender difference in disclosing health problems. Evidence from other studies suggests that men are less likely than women to report minor ailments. ${ }^{12-14}$

\section{Nonresponse}

Survey nonresponse may cause a selection bias in prevalence results. ${ }^{15,16}$ Typically, the nonresponse percentage is used to indicate potential bias: the greater the nonresponse percentage, the greater the likelihood of serious bias. The Italy survey ${ }^{6-9}$ and the Netherlands survey ${ }^{10}$ offer an unusual opportunity to consider the nonresponse problem because the age and sex of each nonresponder were known from up-to-date population registers.

In the Italy survey, the nonresponse would have been $15 \%$ with the full screening (interview and physical tasks), but was instead $9 \%$ because an abbreviated screening (interview only, proxy respondent permitted) was also accepted. This flexibility made possible the inclusion of deceased persons, mentally and physically challenged persons, and others who declined the full screening or were unavailable for it. However, by broadening the participation, the investigators increased the likelihood of misclassifying cases.

In the Netherlands survey, research objectives dictated a different approach to nonresponse. The survey served as the baseline investigation for a longitudinal study that involved extensive and costly medical evaluation of the participants. ${ }^{17}$ It was necessary to keep false negatives and false positives to a minimum; thus, a neurologic examination performed at a central research facility was chosen as the screening method. Persons unwilling or unavailable to undergo the examination were excluded from the survey. By strictly adhering to this screening method, the investigators decreased the likelihood of misclassifying cases but had to accept an increased nonresponse.

Finally, we make several observations about nonresponse. First, in comparing nonresponse in various surveys, it is meaningless to consider percentages without knowing exactly what they refer to (for example, whether proxy respondents are permitted). Second, to summarize nonresponse with a single percentage may be an oversimplification. In both the Italy survey and the Netherlands survey, there was a much higher nonresponse in older persons than in younger persons (Figs. 2 and 3). Third, more stringent response requirements increase respondent burden and lead to higher nonresponse (Figs. 2 and 3). Fourth, nonresponse does not necessarily lead to selection bias. For men in the Italy survey, the prevalence pattern was virtually the same regardless of whether the more stringent or the less stringent response requirement was used (Fig. 2). Fifth, elderly women are a problematic group in terms of nonresponse and selection bias. In both the Italy survey and the Netherlands survey, these women had high levels of nonresponse when the more stringent response requirements were applied (Figs. 2 and 3). This nonresponse may be related to health status. For example, in the Italy survey, the prevalence results suggest that elderly women in poor health were more likely to respond than elderly women in good health.

\section{CONCLUSIONS}

Comparison of prevalence results for PD from different populations can potentially yield important etiologic clues, provided this can be done validly. The optimal methods for diagnosis and screening in epidemiologic surveys of PD depend on the setting and the scientific goals of the research. Moreover, nonresponse occurs to a greater or lesser extent in virtually every survey. Because of these considerations, investigators have a special responsibility to prepare their reports in sufficient detail so an informed reader can understand the essentials of the design and implementation of the research.

Do prevalence comparisons between surveys have diminished value if the surveys used different diagnostic criteria for PD? Yes. To interpret prevalence comparisons in terms of disease risk becomes more difficult. We recommend applying several sets of diagnostic criteria in the same survey. The primary set would generate the major prevalence results, whereas the other sets may be used for prevalence comparisons with other surveys (for example, see reference 2).

Is screening performance affected adversely if symptom questions are answered by one family member for the entire family living together rather than by each fam- 
ily member individually? Perhaps. The likelihood that symptoms of PD are mentioned, especially minor ones, may be lower if one family member responds for the entire family living together. More research is needed on this. In addition, more research is needed to confirm that women are more likely than men to mention symptoms.

Does nonresponse from refusal or unavailability lead to a bias in prevalence results? Not always. However, if a graph of age- and sex-specific prevalence rates of $\mathrm{PD}$ shows a steep rise or precipitous decline for elderly women, then the reader should first consider bias as an explanation.

Acknowledgments: Drs. Walter A. Rocca and Demetrius M. Maraganore were supported in part by NINDS Grant NS33978. Dr. Maarten C. de Rijk was financially supported by the Netherlands Organization for Scientific Research (NWO), Grant SIR 15-1513. The authors thank Drs. Nadir E. Bharucha and Adil E. Bharucha for providing unpublished data from their prevalence survey conducted in Bombay, India. They also thank Drs. Shi-chuo Li and Xue-ming Cheng for making available unpublished data from their prevalence survey conducted in six cities of China. The authors also thank Dr. Leslie Kish for critical discussions about nonresponse, and Dr. Cynthia Leibson for providing some key references. Finally, the authors thank Claudia Castrillon, Shannon McDonnell, and Jack Panossian for their assistance in preparing the manuscript.

\section{REFERENCES}

1. Tanner CM, Langston JW. Do environmental toxins cause Parkinson's disease? A critical review. Neurology 1990;40(suppl 3):1730.

2. Melcon MO, Anderson DW, Vergara RH, Rocca WA. Prevalence of Parkinson's disease in Junín, Buenos Aires Province, Argentina. Mov Disord 1997;12:197-205.

3. Anderson DW, Melcon MO, Vergara RH. Methods for a prevalence survey of neurological disorders in Junín, Buenos Aires, Argentina. Neuroepidemiology 1995;14:110-122.
4. Bharucha NE, Bharucha EP, Bharucha AE, Bhise AV, Schoenberg BS. Prevalence of Parkinson's disease in the Parsi community of Bombay, India. Arch Neurol 1988;45:1321-1323.

5. Li SC, Schoenberg BS, Wang CC, et al. A prevalence survey of Parkinson's disease and other movement disorders in the People's Republic of China. Arch Neurol 1985;42:655-657.

6. Morgante L, Rocca WA, Di Rosa AE, et al. Prevalence of Parkinson's disease and other types of parkinsonism: a door-to-door survey in three Sicilian municipalities. Neurology 1992;42:19011907.

7. Meneghini F, Rocca WA, Grigoletto F, et al. Door-to-door prevalence survey of neurological diseases in a Sicilian population background and methods. Neuroepidemiology 1991;10:70-85.

8. Meneghini F, Rocca WA, Anderson DW, et al. Validating screening instruments for neuroepidemiologic surveys: experience in Sicily. J Clin Epidemiol 1992;45:319-331.

9. Grigoletto F, Anderson DW, Rocca WA, et al. Attrition and use of proxy respondents and auxiliary information in the Sicilian Neuroepidemiologic Study. Am J Epidemiol 1994;139:219-228.

10. de Rijk MC, Breteler MMB, Graveland GA, et al. Prevalence of Parkinson's disease in the elderly: the Rotterdam Study. Neurology 1995;45:2143-2146.

11. Last JM, ed. A Dictionary of Epidemiology. New York, NY: Oxford University Press, 1983.

12. Schroll M, Ferry M, Lund-Larsen K, Enzi G. Assessment of health: self-perceived health, chronic diseases, use of medicine. Eur J Clin Nutr 1991;45(suppl 3):169-182.

13. Harris RB, Weissfeld LA. Gender differences in the reliability of reporting symptoms of angina pectoris. J Clin Epidemiol 1991;44: 1071-1078.

14. Novy DM, Nelson DV, Averill PM, Berry LA. Gender differences in the expression of depressive symptoms among chronic pain patients. Clinical Journal of Pain 1996;12:23-29.

15. Kish L. Survey Sampling. New York, NY: John Wiley \& Sons, Inc, 1965.

16. Moser CA, Kalton G. Survey Methods in Social Investigation, 2nd ed. Aldershot, Hants, England: Gower Publishing Co, Ltd, 1979.

17. Hofman A, Grobbee DE, de Jong PTVM, van den Ouweland FA Determinants of disease and disability in the elderly: the Rotterdam Elderly Study. Eur J Epidemiol 1991;7:403-422. 